
Kidney
Blood Pressure
Research

Kidney Blood Press Res 2013;37:58-67

DOI: 10.1159/000343400

Published onIIne: IVarch 17, 2013

(C) 2013 S. Karger AG, Basel

www.karger.com/kbr

Accepted: February 18, 2013

1423-0143/13/0371-0058\$38.00/0

This is an Open Access article licensed under the terms of the Creative Commons AttributionNonCommercial-NoDerivs 3.0 License (http://www.karger.com/OA-license), applicable to the online version of the article only. Distribution for non-commercial purposes only.

\title{
Calf Bioimpedance Spectroscopy for Determination of Dry Weight in Hemodialysis Patients: Effects on Hypertension and Left Ventricular Hypertrophy
}

\author{
Eric Seibert ${ }^{\mathrm{a}, \mathrm{e}}$ Stephan G. Müller ${ }^{\mathrm{b}}$ Peter Fries ${ }^{\mathrm{c}}$ Johanna Pattmöller ${ }^{\mathrm{b}}$ \\ Oliver Kuss $^{d}$ Gunnar H. Heine ${ }^{b}$ Matthias Girndt ${ }^{a}$ Günther Schneider ${ }^{c}$ \\ Peter Kotanko ${ }^{e}$ Fansan Zhue Nathan W. Levine Martin K. Kuhlmanne,f \\ anternal Medicine II, Martin-Luther-University Medical Centre, Halle, Germany; 'bnternal Medicine IV, \\ University of Saarland Medical Centre, Homburg, Germany; ' Clinic of Diagnostic and Interventional \\ Radiology, University of Saarland Medical Centre, Homburg, Germany; Institute of medical \\ Epidemiology, Biostatistics \& Informatics, University of Halle-Wittenberg, Halle, Germany; ${ }^{\text {eRenal }}$ \\ Research Institute, New York, United States; ${ }^{f}$ Nephrology, Vivantes Clinic Friedrichshain, Berlin, Germany
}

\section{Key Words}

Bioelectrical impedance • Dialysis $\bullet$ Dry weight $\bullet$ Hypertension $\bullet$ Left ventricular hypertrophy

\begin{abstract}
Background/Aims: Dry weight estimation in hemodialysis patients is still a substantial problem. Despite meticulous clinical assessment, fluid overload is common, leading to hypertension and left ventricular hypertrophy (LVH). Segmental calf bioimpedance spectroscopy (cBIS) is a novel tool for dry weight assessment. Here we tested the hypothesis, that its clinical routine use reduces arterial hypertension and left ventricular mass. Methods: Left ventricular mass (determined by magnetic resonance imaging), blood pressure and antihypertensive medication (defined daily doses, ddd) were assessed at baseline (BL). Thereafter post-dialytic target weight was reduced until CBIS-defined dry weight was reached (DW). During a 6-month follow up, DW was re-evaluated monthly by cBIS and end-dialytic weight was adjusted correspondingly. At the end, left ventricular mass, blood pressure and antihypertensive medication were determined a $3^{\text {rd }}$ time (follow-up, FU). Results: Eleven out of 15 patients were available for analysis after 6 months. Left ventricular mass showed a declining trend during the study period (Mean \pm SD; BL 145 $\pm 54 \mathrm{~g}$; DW 142 $\pm 55 \mathrm{~g}$; FU 137 $\pm 52 \mathrm{~g}$; $p=0.61$, linear mixed model). Comparable results were obtained for systolic blood pressure
\end{abstract}




\section{Kidney Blood Pressure Research}

(BL 158 $\pm 18 \mathrm{mmHg}$; DW $144 \pm 19 \mathrm{mmHg} ; \mathrm{FU} 149 \pm 21 \mathrm{mmHg} ; \mathrm{p}=0.07$ ), and antihypertensive medication (BL 3.28 $\pm 2.82 \mathrm{ddd}$; DW 2.86 $\pm 2.81 \mathrm{ddd}$; FU 3.36 $\pm 3.05 \mathrm{ddd} ; \mathrm{p}=0.37$ ). Conclusions: We conclude that attainment of dry weight assessed by CBIS tends to reduce left ventricular mass and blood pressure while antihypertensive medication remains unchanged. While the study was underpowered, its results provide an important hypothesis generating data basis for the design of larger studies.

Copyright (C) 2013 S. Karger AG, Basel

\section{Introduction}

Cardiovascular disease burden is still substantially higher in hemodialysis (HD) patients than in the general population. In an US renal data system database analysis, patients on hemodialysis had a 20-400 fold higher probability to die when compared to the age-matched general population [1]. Among a variety of risk factors, extracellular volume (ECV) overload, initiated predominantly by increased sodium intake and followed by thirst, is the usual state of affairs in HD patients [2]. Therefore, the concept of dry weight is a major component of prescription of HD treatments in end stage renal disease. Fluid overload is associated with hypertension, congestive heart failure and cardiac mortality [3], while volume depletion increases the risk of intradialytic hypotension and also mortality. Various methods have been developed to improve clinical assessment of dry weight, such as biochemical markers, vena cava diameter, whole body bioimpedance analysis and blood volume monitoring, but none of these proved useful as sole tools, in part because of the absence of a definitive reference $[4,5]$.

Our group established that monitoring the electrical resistance of the calf during HD using continuous bioimpedance spectroscopy (cBIS) allows the assessment of changes in ECV of the calf, since decrease of ECV will increase calf-resistance [6, 7]. The calf is chosen for monitoring of changes in extracellular resistance $\left(\mathrm{R}_{\mathrm{E}}\right)$ (and therefore in ECV), because due to gravity in ambulatory patients the ECV is greater in the legs than in arms and trunk. Therefore, it is assumed, that the calf is the last source of fluid to feed the intravascular space during ongoing ultrafiltration, when other compartments are no longer able to contribute further [8]. During HD calf extracellular resistance $\left(\mathrm{CR}_{\mathrm{E}}\right)$ steadily increases with ongoing ultrafiltration (UF) until excessive ECV of the calf has been completely removed. We have documented that at this point calf resistance does not further increase despite of continued UF. Stabilization of the calf-resistance slope ("flattening") occurs at weights higher than that, where clinical symptoms (e.g. cramps or hypotension) due to hypovolemia occur $[6,7,9]$. Flattening of calf-resistance curves during dialysis can therefore be used as an indicator of dry weight. However, the method has certain limitations, especially in patients with persistent edema due to other pathologies than plain overhydration (e.g. cardiac edema, low serum protein). Here, the combination of two parameters, slope of the $\mathrm{cR}_{\mathrm{E}}$-curve and normalized resistivity, provides useful information on both kinetic and static hydration states, allowing the detection of DW in most patients $[6,7,10,11]$.

We previously demonstrated that targeting dry weight with the cBIS methodology reduced end-dialytic weight markedly. In this pilot study we therefore tested the hypothesis, that attainment of DW with routine use of cBIS results in a reduction of blood pressure and $\mathrm{LVH}$ in hemodialysis patients.

\section{Subjects and Methods}

\section{Patient Population}

Fifteen chronic hemodialysis patients (5 males) from the outpatient dialysis facility of the University 


\section{Kidney \\ Blood Pressure Research}

Table 1. Anthropometrics and characteristics of dialysis treatments at baseline

Seibert et al.: cBIS Reduces Hypertension and LVH in HD Patients

\begin{tabular}{lcc}
\hline & Mean \pm SD & Range [Min/Max] \\
\hline Age [yrs] & $59 \pm 12.9$ & $29 / 82$ \\
Height [cm] & $165 \pm 8.6$ & $150 / 178$ \\
BMI [kg/m ${ }^{2}$ ] & $24.9 \pm 4$ & $16.8 / 30.9$ \\
Clinical Dry Weight [kg] & $68.3 \pm 13$ & $44 / 84$ \\
Dialysis vintage [months] & $44.8 \pm 30$ & $11 / 105$ \\
Dialysis time [min] & $239 \pm 23$ & $210 / 300$ \\
Ultrafiltration volume [ml] & $2048 \pm 970$ & $600 / 2900$ \\
Ultrafiltration rate [ml/h] & $507 \pm 214$ & $150 / 773$ \\
\hline
\end{tabular}

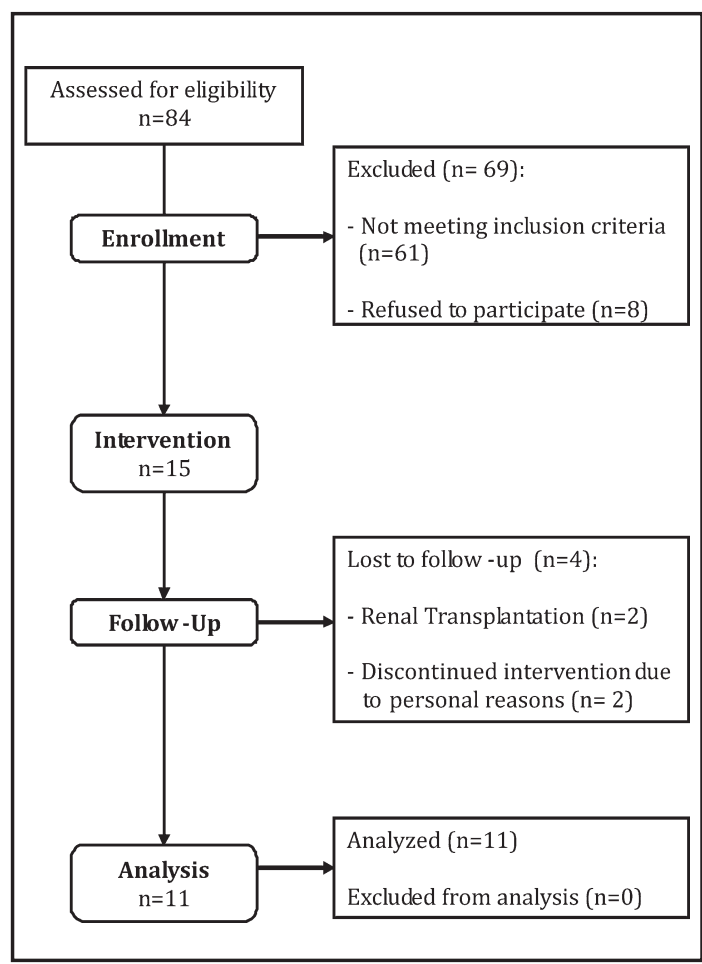

Fig. 1. Participant flow chart.
Hospital of the Saarland at Homburg/Saar, Germany, a non-profit clinical dialysis centre, were recruited into a prospective clinical trial (fig. 1). Patients were eligible if they were on stable hemodialysis treatment for $>3$ months, and if they were 18-80 years of age and capable to communicate sufficiently to understand research procedures and provide signed written informed consent. Excluded were patients with concomitant participation in another interventional trial, psychiatric disorders preventing from valid informed consent, pregnancy or lactation, heart failure stage NYHA IV, a history of acute myocardial infarction or major stroke within the last 6 months, a history of lower extremity amputation and those with cardiac pacemakers, implanted electrical pumps and implanted knee or hip joints.

End-stage renal disease was due to diabetic nephropathy $(n=2)$, glomerulonephritis $(\mathrm{n}=1)$, nephrosclerosis $(\mathrm{n}=3)$, polycystic kidney disease $(n=3)$, interstitial nephritis $(n=2)$, reflux nephropathy $(n=2)$, ischemic renal failure $(n=1)$ and traumatic renal failure $(\mathrm{n}=1)$. Hemodialysis was performed thrice weekly using bicarbonate dialysate and polyamide or polysulfone dialysers. All patients were of Caucasian ethnicity. Anthropometrics and characteristics of the dialysis treatments are given in table 1.

11 out of 15 patients were followed over $>6$ months. 4 patients ( 2 males) were lost to follow-up due to renal transplant $(n=2)$ or personal reasons $(n=2)$ and could not be assessed at follow-up after 6 months.

\section{Study Design}

Study approval was obtained from the Ethical Review Board of the professional body of doctors of the Saarland. Written informed consent was obtained from each patient. All investigators adhered to the Declaration of Helsinki. The Trial was registered in the US National Library of Medicine's registry (NCT00397306, http://clinicaltrials.gov). Enrolment was conducted by investigators during routine visits. The study protocol was similar to previous studies $[6,7,9,10]$ with additional parameters being assessed. In short, following baseline (BL) measurements, the end-dialytic target weight was reduced stepwise in consecutive treatments by 0.2 to 0.5 kilograms, until $\mathrm{cR}_{\mathrm{E}}$ stabilized despite ongoing $\mathrm{UF}$ and normalized resistivity was within a normal range, indicating BIS-estimated dry weight (DW). Stabilization of calfresistance was defined as a change of $\mathrm{cR}_{\mathrm{E} 0} / \mathrm{CR}_{\mathrm{Et}}$-Ratio of less than $1 \%$ within 20 minutes (corresponding to $<0.05 \% / \mathrm{min}$ ). $\mathrm{cR}_{\mathrm{E} 0}$ represents $\mathrm{cR}_{\mathrm{E}}$ at the beginning of $\mathrm{HD}$ and $\mathrm{cR}_{\mathrm{Et}}$ represents $\mathrm{cR}_{\mathrm{E}}$ at any time t. Resistivity of the measured calf segment was normalized to BMI and considered being in the gender-specific normal range in males $>18.5 \cdot 10^{-2} \Omega \mathrm{m}^{3} \mathrm{~kg}^{-1}$ and in females $>19.1 \cdot 10^{-2} \Omega \mathrm{m}^{3} \mathrm{~kg}^{-1}$, respectively, as described before [10]. After achievement of DW, in the next two consecutive dialysis treatments, end-dialytic target weight 


\section{Kidney Blood Pressure Research}

Fig. 2. cBIS measurement at DW (example). Flattening of the $\mathrm{cR}_{\mathrm{E} 0} /$ $\mathrm{CR}_{\mathrm{Et}}$-Ratio is observed at $201 \mathrm{~min}$. Grey line represents raw data, black line represents filtered data. Note artefacts in raw data due to a leg position change at 130-150 $\min$.

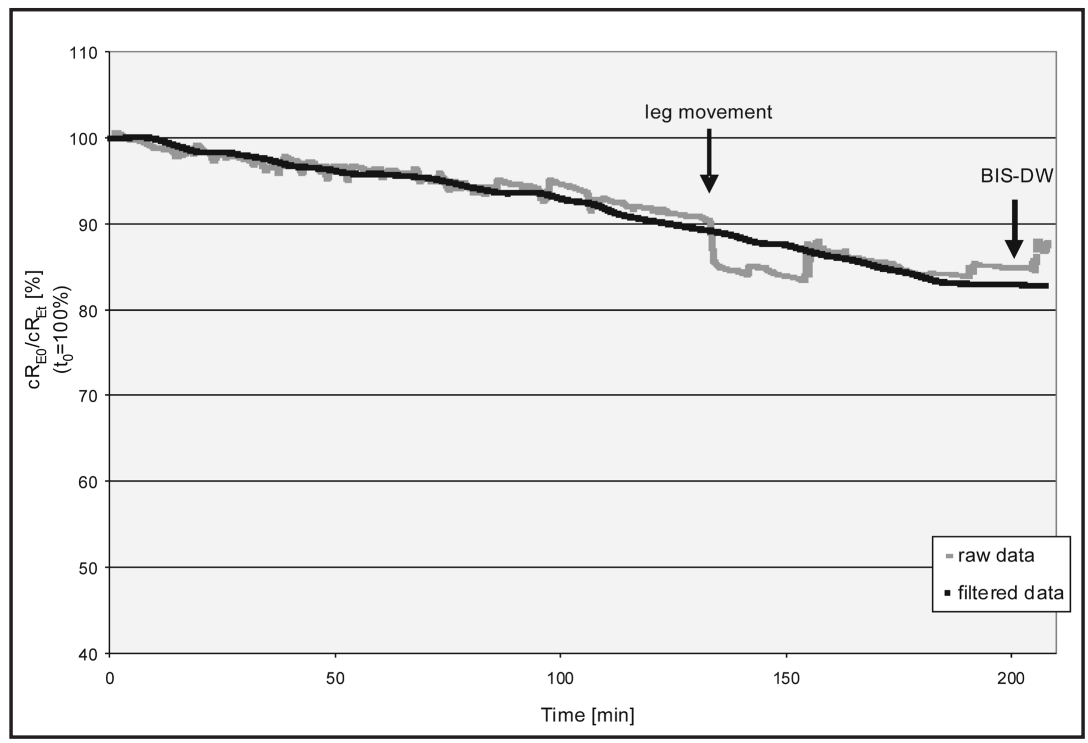

was not changed in order to confirm DW with two additional measurements. After that, following clinical practice, patient's weight was carefully further reduced until some clinical symptoms of hypovolemia occurred (symptom weight). Patient's weight was then increased again to the BIS-estimated dry weight. In the following period, DW was reassessed once a month and end-dialytic target weight was adjusted if necessary. After 6 months all outcome measures were assessed again, being the end point of the study (follow-up, FU).

\section{Outcome Measures}

Changes in $\mathrm{CR}_{\mathrm{E}}$ were monitored and recorded continuously during dialysis using a multifrequency bioimpedance spectroscope (Xitron Technologies, San Diego, CA). For cBIS an alternate current with frequencies ranging from $1 \mathrm{kHz}$ to $300 \mathrm{kHz}$ was applied using electrode positions as described previously [7]. On average, measurements were taken every 15 seconds. Data analysis was performed online during dialysis treatments. The recorded curves reflect the ratio of $\mathrm{cR}_{\mathrm{E}}$ at time 0 divided by $\mathrm{cR}_{\mathrm{E}}$ at any time $\mathrm{t}_{\left(\mathrm{CR}_{\mathrm{E} 0} /\right.}$ $\mathrm{CR}_{\mathrm{Et}}$ expressed in $\%, \mathrm{t}_{0}=100 \%$, example in fig. 2). They represent a reciprocal measure of relative calf extracellular resistance at any time $t$, which corresponds to relative calf extracellular volume as resistance increases with decreasing calf ECV. For reduction of artefacts due to leg movements, a digital filter with a slope moving average technique was used as described before [6].

The following outcome measures were determined at baseline, after achievement of DW and after 6 months of follow up:

I. Blood pressure. At every hemodialysis treatment, blood pressure was assessed non-invasively (Dinamap ProCare, General Electric Healthcare, Munich, Germany, cuff sizes according to upper arm circumference, size 1: $27-35 \mathrm{~cm}$, size $2: 34-43 \mathrm{~cm}$ ) before and after treatment at the contralateral arm of the dialysis fistula. Patients were in dorsal elevated position. Mean values of three repeated measurements within 15 Minutes were used for further analysis.

II. Antihypertensive Medication. Antihypertensive medication was assessed by direct interview in combination with chart review. Medication was quantified using the Anatomical Therapeutic Chemical (ATC) classification system and the defined daily dose (ddd) as a measuring unit [12] as recommended by the WHO for drug utilization studies. Doses are given as multiples of ddd.

III. Parameters of Myocardial Mass and Myocardial Function by cardiac magnetic resonance imaging (MRI). All MRI examinations were performed on a 1.5 Tesla system (Magnetom Avanto, Siemens Medical Systems, Erlangen, Germany) using a phased-array surface coil. 


\section{Kidney \\ Blood Pressure Research}

For cine imaging of the heart we acquired retrospectively ECG-gated steady state free precession sequences with a repetition time (TR) of $45.9-47.4 \mathrm{~ms}$, an echo time (TE) of $1.5-1.6 \mathrm{~ms}$, a flip angle (alpha) of $65^{\circ}$ and a slice thickness of $6 \mathrm{~mm}$ with 25 reconstructed cardiac frames. For assessment of cardiac function consecutive slices in four chamber view and short axis orientation were acquired without gap from base to apex covering both the left and right ventricles and atria.

All acquired data were transferred to an external workstation (Leonardo, Siemens Medical Systems, Erlangen, Germany) for quantitative analysis using dedicated software (ARGUS, Siemens).

Endocardial borders of the left and right ventricle as well as the epicardial outline of the left ventricle were marked by manual contouring at end diastole and end systole. The end diastolic (EDV) and end systolic volumes (ESV) of the left and right ventricle were determined as previously described [13-16]. The EDV and ESV were used to determine stroke volume (SV) and ejection fraction (EF). LV and RV mass were determined by summation of EDVs within the epicardial and endocardial borders of the short-axis slices and multiplying the myocardial tissue volume by its specific density of $1.05 \mathrm{~g} \cdot \mathrm{cm}^{-3}$ :

Myocardial mass $=1.05 \bullet \sum_{\text {slices }}$ thk $\bullet\left(A_{\text {epi }}-A_{\text {endo }}\right)$

where thk represents layer thickness $(10 \mathrm{~mm}) ; A_{e p i}$ represents epicardial area; and $A_{\text {endo }}$ endocardial area.

\section{Statistical Analyses}

For descriptive purposes, variables are given as means and standard deviations. The time course of the three primary outcome parameters (systolic blood pressure (SBP), antihypertensive medication, left ventricular mass) was assessed within linear mixed models with the time point (baseline, DW, follow-up) as a categorical covariate while accounting for repeated within-subject measurements by including a random effect. All data were analyzed using the SAS ${ }^{\circledR}, \mathrm{V} 9.1$ (SAS Institute Inc., Cary, NC, USA).

\section{Results}

Baseline weight was $68.3 \pm 13.0 \mathrm{~kg}$. After $6.33 \pm 4.12$ treatments DW was achieved at $142.8 \pm 41.0 \mathrm{~min}$. DW was $67.4 \pm 12.7 \mathrm{~kg}$. On average, symptoms occurred when weight was further reduced by $0.74 \pm 0.38 \mathrm{~kg}$ (fig. 3), confirming the idea that DW is close to the elusive "true" dry weight while keeping a reasonable safety distance to the point where patients get at risk.

\section{Blood pressure measurements}

Table 2 gives an overview on the results of blood pressure measurements. Systolic blood pressure (SBP) before dialysis was reduced markedly from BL to BIS-DW from $157.9 \pm 17.5$ to $143.8 \pm 19 \mathrm{mmHg}$. At FU SBP tended to rise slightly to $149 \pm 20.9 \mathrm{mmHg}$ ( $\mathrm{p}=0.07$, fig. 4). Comparable results were obtained for diastolic blood pressure (DBP, $81.7 \pm 11.2 \mathrm{mmHg}, 77.2$ $\pm 9.2 \mathrm{mmHg}$ and $79.4 \pm 10.3 \mathrm{mmHg}, \mathrm{p}=0.29)$, mean arterial pressure $(107.1 \pm 11.6 \mathrm{mmHg}$, $99.1 \pm 9.6 \mathrm{mmHg}$ and $101.2 \pm 10.2 \mathrm{mmHg}, \mathrm{p}=0.09)$ and heart rate $\left(74 \pm 10 \mathrm{~min}^{-1}, 68 \pm 9 \mathrm{~min}^{-1}\right.$ and $71 \pm 10 \mathrm{~min}^{-1}, \mathrm{p}=0.01$ ).

Post dialysis SBP remained stable throughout the study period (BL $149.1 \pm 23.6 \mathrm{mmHg}$, BIS-DW $145.3 \pm 29.2 \mathrm{mmHg}$, FU $148 \pm 25.1 \mathrm{mmHg}$, $\mathrm{p}=0.86$ ) while DBP (BL $80.5 \pm 11.2 \mathrm{mmHg}$, BIS-DW $81.7 \pm 11.6 \mathrm{mmHg}$, FU $75.4 \pm 11.3 \mathrm{mmHg}, \mathrm{p}=0.22$ ), mean arterial pressure (BL 103.4 $\pm 12.8 \mathrm{mmHg}$, BIS-DW $103.3 \pm 15.6 \mathrm{mmHg}$, FU $99.6 \pm 12.6 \mathrm{mmHg}, \mathrm{p}=0.61$ ) and heart rate (BL $73.1 \pm 8.4 \mathrm{~min}^{-1}$, BIS-DW $71.5 \pm 12.2 \mathrm{~min}^{-1}$, FU $69.1 \pm 12.2 \mathrm{~min}^{-1}, \mathrm{p}=0.11$ ) tended to decline without reaching statistical significance.

\section{Antihypertensive medication}

Table 3 gives an overview on the antihypertensive medication needs throughout the study. At BL mean ddd of antihypertensive drugs was 3.28 \pm 2.82 . At DW those drugs could 


\section{Kidney \\ Blood Pressure Research}

\section{Kidney Blood Press Res 2013;37:58-67}

DOI: $10.1159 / 000343400$

Published onIIne: IVarch 17, 2013

(C) 2013 S. Karger AG, Base

www.karger.com/kbr

Table 2. Results of blood pressure and heart rate assessment

\begin{tabular}{lcccc}
\hline & BL & DW & FU & $\begin{array}{c}\text { p-value } \\
\text { (time effect) }\end{array}$ \\
\hline pre HD: blood pressure [mmHg] & $157.9 \pm 17.5$ & $143.8 \pm 19$ & $149 \pm 20.9$ & 0.07 \\
$\quad$ systolic & $81.7 \pm 11.2$ & $77.2 \pm 9.2$ & $79.4 \pm 10.3$ & 0.29 \\
$\quad$ diastolic & $107.1 \pm 11.6$ & $99.1 \pm 9.6$ & $101.2 \pm 10.2$ & 0.09 \\
MAP & $74.7 \pm 9.6$ & $67.7 \pm 8.9$ & $71.5 \pm 9.8$ & 0.01 \\
HR [min ${ }^{-1}$ ] & & & $148 \pm 25.1$ & 0.86 \\
post HD: blood pressure [mmHg] & $149.1 \pm 23.6$ & $145.3 \pm 29.2$ & $75.4 \pm 11.3$ & 0.22 \\
systolic & $80.5 \pm 11.2$ & $81.7 \pm 11.6$ & $99.6 \pm 12.6$ & 0.61 \\
diastolic & $103.4 \pm 12.8$ & $103.3 \pm 15.6$ & & 0.11 \\
MAP & $73.1 \pm 8.4$ & $71.5 \pm 12.2$ & $69.1 \pm 12.2$ & \\
HR [min ${ }^{-1}$ ] & & & \\
\hline MAP = mean arterial pressure, HR= heart rate
\end{tabular}

Table 3. Antihypertensive medication needs throughout the study

\begin{tabular}{lccc}
\hline & BL & DW & FU \\
\hline mean \pm SD & $3.28 \pm 2.82$ & $2.86 \pm 2.81$ & $3.36 \pm 3.05$ \\
lower 95 \% CI & 1.72 & 1.3 & 1.31 \\
upper 95 \% CI & 4.84 & 4.41 & 5.41 \\
\hline
\end{tabular}

All values given in ddd (daily defined doses). Time effect $\mathrm{p}=0.37$

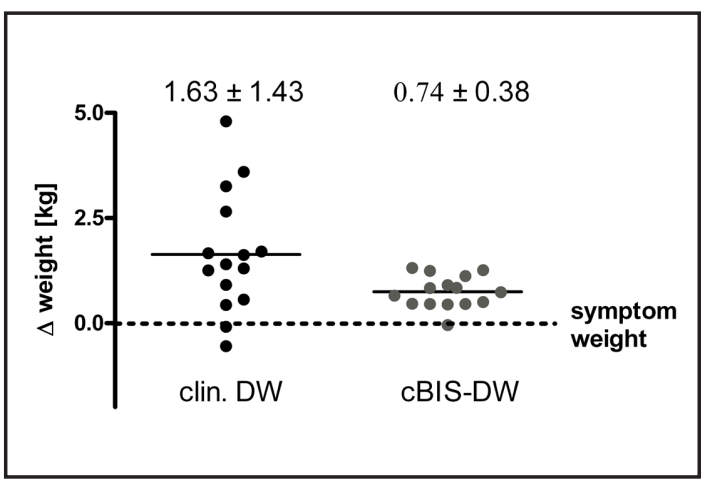

Fig. 3. Differences between symptom weight, clinically estimated dry weight (clin. DW) and cBIS estimated dry weight (cBIS-DW).

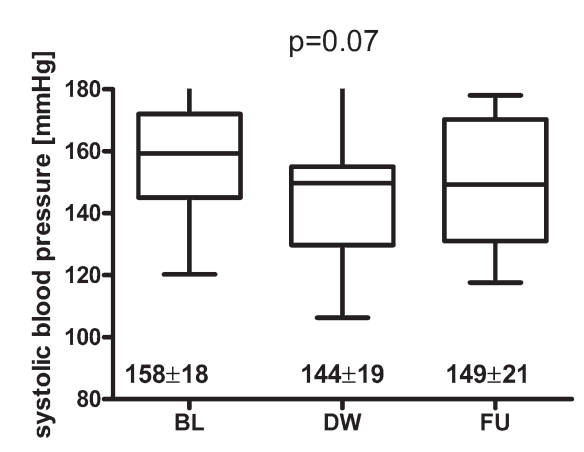

Fig. 4. Systolic blood pressure before dialysis.

be reduced to $2.86 \pm 2.81 \mathrm{ddd}$. During the following 6-month period dosage rose again to $3.36 \pm 3.05$ ddd at $\mathrm{FU}(\mathrm{p}=0.37)$.

\section{Ventricular mass, volume, and function}

Table 4 gives an overview on the results of cardiac parameters assessed by MRI throughout the study. Myocardial mass was reduced from $145 \pm 54 \mathrm{~g}$ at BL to $142 \pm 55 \mathrm{~g}$ at DW and $137 \pm 52 \mathrm{~g}$ at $\mathrm{FU}$ ( $\mathrm{p}=0.61$, fig. 5). Normalization on body surface area did not affect this result (BL $82.11 \pm 30.43 \mathrm{~g} / \mathrm{m}^{2}$, DW $81.07 \pm 32.36 \mathrm{~g} / \mathrm{m}^{2}$, FU $78.72 \pm 29.37 \mathrm{~g} / \mathrm{m}^{2}, \mathrm{p}=0.71$ ). EDV of the left ventricle markedly decreased from BL to DW and tended to rise a little upon FU but remained below BL values (BL $101.53 \pm 34.74 \mathrm{ml}$, DW $88.58 \pm 22.12 \mathrm{ml}$, FU $92.66 \pm$ $22.25 \mathrm{ml}, \mathrm{p}=0.14$ ). The same applies for ESV (BL $40.13 \pm 23.04 \mathrm{ml}$, DW $33.44 \pm 14.05 \mathrm{ml}, \mathrm{FU}$ $36.66 \pm 14.52 \mathrm{ml}, \mathrm{p}=0.24$ ) and SV (BL $61.4 \pm 17.56 \mathrm{ml}$, DW 55.11 $\pm 11.63 \mathrm{ml}$, FU $56.01 \pm 14.48$ $\mathrm{ml}, \mathrm{p}=0.21$ ).

All examined volumes of the right ventricle constantly decreased throughout the study period (EDV: BL $75.05 \pm 22.28 \mathrm{ml}$, DW $70.87 \pm 22.98 \mathrm{ml}$, FU $63.24 \pm 15.08 \mathrm{ml}, \mathrm{p}=0.16$; ESV: BL $33.95 \pm 14.29 \mathrm{ml}$, DW $32.17 \pm 10.97 \mathrm{ml}$, FU $27.42 \pm 6.69 \mathrm{ml}, \mathrm{p}=0.27$; SV: BL $41.1 \pm 14.85 \mathrm{ml}$, 


\section{Kidney \\ Blood Pressure Research}

Table 4. Changes in cardiac MRI parameters

\begin{tabular}{|c|c|c|c|c|}
\hline & BL & DW & FU & $\begin{array}{c}p \text {-value } \\
\text { (time effect) }\end{array}$ \\
\hline \multicolumn{5}{|l|}{ left ventricle } \\
\hline myocardial mass [g] & $145.24 \pm 53.76$ & $141.99 \pm 54.91$ & $137.33 \pm 52.18$ & 0.61 \\
\hline LVMI $\left[\mathrm{g} / \mathrm{m}^{2}\right]$ & $82.11 \pm 30.43$ & $81.07 \pm 32.36$ & $78.72 \pm 29.37$ & 0.71 \\
\hline $\mathrm{EF}[\%]$ & $61.79 \pm 9.00$ & $63.2 \pm 8.11$ & $61.16 \pm 10.14$ & 0.66 \\
\hline \multicolumn{5}{|l|}{ volumes [ml] } \\
\hline EDV & $101.53 \pm 34.74$ & $88.58 \pm 22.12$ & $92.66 \pm 22.25$ & 0.14 \\
\hline ESV & $40.13 \pm 23.04$ & $33.44 \pm 14.05$ & $36.66 \pm 14.52$ & 0.24 \\
\hline SV & $61.4 \pm 17.56$ & $55.11 \pm 11.63$ & $56.01 \pm 14.48$ & 0.21 \\
\hline \multicolumn{5}{|l|}{ right ventricle } \\
\hline $\mathrm{EF}[\%]$ & $55.16 \pm 10.39$ & $54.73 \pm 5.67$ & $55.81 \pm 8.99$ & 0.94 \\
\hline \multicolumn{5}{|l|}{ volumes [ml] } \\
\hline EDV & $75.05 \pm 22.28$ & $70.87 \pm 22.98$ & $63.24 \pm 15.08$ & 0.16 \\
\hline ESV & $33.95 \pm 14.29$ & $32.17 \pm 10.97$ & $27.42 \pm 6.69$ & 0.27 \\
\hline SV & $41.1 \pm 14.85$ & $38.7 \pm 13.02$ & $35.82 \pm 11.68$ & 0.30 \\
\hline
\end{tabular}

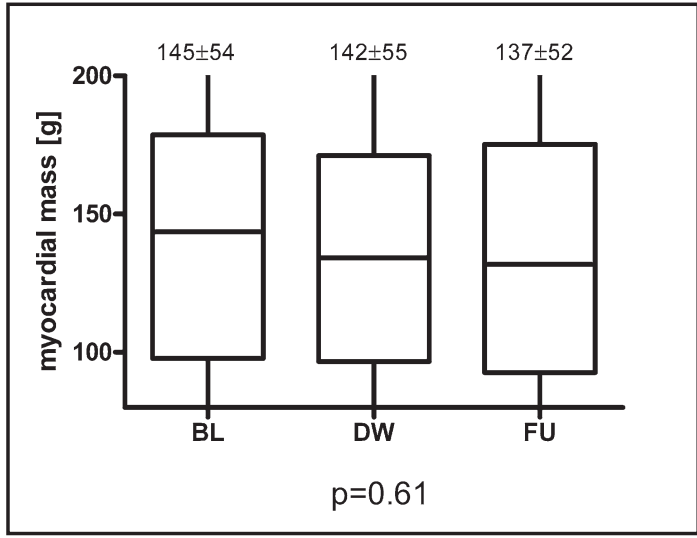

Fig. 5. Left ventricular mass.

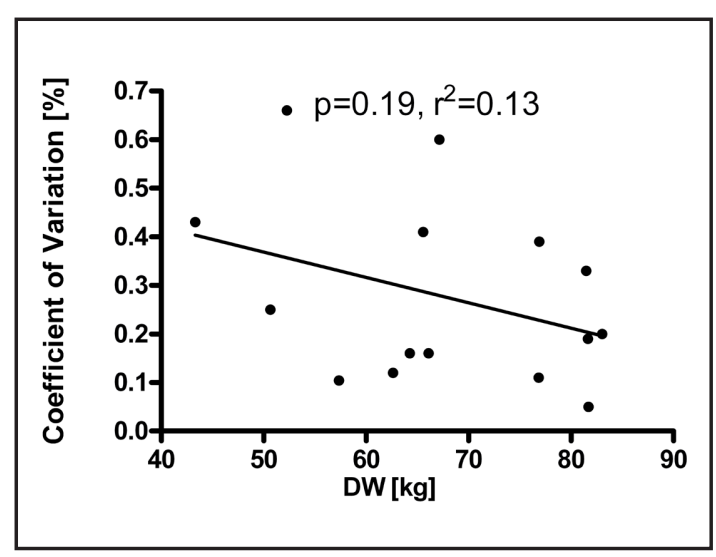

Fig. 6. Coefficients of variation of 3 repeated DW estimations by cBIS.

DW $38.7 \pm 13.02 \mathrm{ml}, \mathrm{FU} 35.82 \pm 11.68 \mathrm{ml}, \mathrm{p}=0.3$ ). Time effect was not significant for any MRI parameter due to insufficient statistical power given the small number of subjects.

\section{Measurement reproducibility}

Mean coefficient of variation in three consecutive treatments at DW was $0.26 \pm 0.15 \%$. This would resemble in an average $75 \mathrm{~kg}$ patient to only $0.195 \mathrm{~kg}$. Coefficients of variation were not dependent on absolute body weight ( $p=0.19, R^{2}=0.13$, fig. 6).

\section{Discussion}

LVH is an independent risk factor for sudden cardiac death, heart failure and cardiac arrhythmias in chronic uraemia and the general population [17-19]. Among the main determinants of LVH in HD patients are end-diastolic left ventricular volume and pre dialysis blood pressure [20] that are mainly influenced by pre dialysis volume overload. Blood pressure reduction may mediate salutary effects on LVH [21]. In our pilot study we tested 


\section{Kidney Blood Pressure Research}

Kidney Blood Press Res 2013;37:58-67

DOI: $10.1159 / 000343400$

Publisned onIIne: VIarch 17, 2013

Seibert et al.: cBIS Reduces Hypertension and LVH in HD Patients

in a small cohort of HD patients the hypothesis, that cBIS, a promising novel technique for dry weight determination, allows reduction of left ventricular mass and pre dialysis blood pressure. As patients serve as their own controls, no normal values derived from healthy populations have to be used for dry weight assessment. Therefore, end-dialytic weight can be prescribed very close to physiologic hydration states. We used cardiac MRI to determine changes in cardiac morphology and function when cBIS instead of clinical routine estimation is used for determination of dry weight. As the pilot trial was clearly underpowered, statistical testing of our hypothesis did not reach statistical significance, albeit the data shows clear improvements in the main outcome parameters within a biologically important range. Left ventricular mass, end-diastolic left ventricular volume and pre dialysis blood pressure declined markedly. These effects occurred without relevant concomitant increase in antihypertensive medication. There was even a tendency in reduction of antihypertensive drugs between BL and DW and during that time systolic blood pressure dropped the most. This is very likely due to strict volume control and is consistent with our previous findings [7] and the 2009 study from Agarwal et al. [22] that demonstrated that reduction of dry weight is effective in improving blood pressure control in hypertensive HD patients. The observed slight incline between DW and FU might be explained in a less strict volume control as cBIS measurements were performed only once a month after achievement of dry weight. However the documented effect on systolic/diastolic blood pressure of $-14 /-5 \mathrm{mmHg}$ at DW and of $-9 /-3 \mathrm{mmHg}$ after 6 months of follow-up is comparable with the administration of an additional antihypertensive drug.

Albeit our population had some degree of hypertension at baseline, it has also been shown for less hypertensive patients, that use of cBIS determined dry weight is able to reduce blood pressure further towards normotensive ranges. Unfortunately, in that study no data on LVH or antihypertensive medication needs have been recorded. However, the reduction in blood pressure was more pronounced than in a group of patients that had not yet reached cBIS-DW in the same study. Therefore, one can conjecture that also patients with mild hypertension might benefit from dry weight estimation by means of cBIS [11].

Additionally, it was reported earlier, that heart rate is an independent prognostic factor for mortality in HD patients [23]. The significant reduction in pre dialysis heart rate in our study combined with the reduction of LVH further supports the presumption of positive effects of volume control in hemodialysis patients. One might speculate that it results from reduced sympathetic overactivity, a condition that is both frequently observed in dialysis patients [24] and closely related to LVH [25]. Myocardial mass and left ventricular mass index dropped constantly throughout the study. Being a long-term consequence of eliminated volume overload one could speculate, that they would even regress further but our data does not support this assumption as the follow-up was terminated at 6 months.

\section{Limitations}

24-hour ambulatory blood pressure measurements would have been preferable over incenter measurements before and after dialysis. However, within the limits of this otherwise technical and timewise demanding pilot study, mean values of three repeated measurements within 15 minutes were satisfactory to draw first conclusions.

Another limitation of the study is the small number of patients which is in part outweighed by the large number of actual HD sessions investigated.

\section{Conclusion}

We conclude that cBIS for determination of dry weight in hemodialysis patients is safe, reproducible and may reduce hypertension and left ventricular hypertrophy. Further adequately powered, large-scale and long-term studies with clinical endpoints are justified to explore the definite benefits of determination of dry weight with cBIS in respect of cardiovascular disease burden in hemodialysis patients. 


\section{Kidney \\ Blood Pressure Research}

Seibert et al.: cBIS Reduces Hypertension and LVH in HD Patients

\section{Conflict of Interests}

PK and NWL hold stock in Fresenius Medical Care. All other authors declare that they don't have any competing financial interests.

The manuscript has not been published and is not being considered for publication elsewhere, in whole or in part, in any language, except as an abstract.

\section{Acknowledgements}

We thank F. Lizzi for study organization and administrative oversight. Study equipment (bioimpedance spectroscopes and recording software) was sponsored in part by the Renal Research Institute, New York, United States. This work was solely funded by intramural sources and did not receive any grant from the industry, the public or not-for-profit sector.

\section{References}

1 Foley RN, Parfrey PS, Sarnak MJ: Clinical epidemiology of cardiovascular disease in chronic renal disease. Am J Kidney Dis 1998;32:S112-S119.

-2 Seibert E, Kuhlmann MK, Levin NW: Modifiable Risk Factors for Cardiovascular Disease in CKD Patients. Contrib Nephrol 2005;149:219-229.

3 Wizemann V, Wabel P, Chamney P, Zaluska W, Moissl U, Rode C, Malecka-Masalska T, Marcelli D: The mortality risk of overhydration in haemodialysis patients. Nephrol Dial Transplant 2009;24:1574-1579.

4 Charra B, Laurent G, Chazot C, Calemard E, Terrat JC, Vanel T, Jean G, Ruffet M: Clinical assessment of dry weight. Nephrol Dial Transplant 1996;11:16-19.

5 Jaeger JQ Mehta RL: Assessment of Dry Weight in Hemodialysis: An Overview. J Am Soc Nephrol 1999;10:392-403.

6 Zhu F, Kuhlmann MK, Kotanko P, Seibert E, Leonard EF, Levin NW: A method for the estimation of hydration state during hemodialysis using a calf bioimpedance technique. Physiol Meas 2008;29:S503-516.

7 Zhu F, Kuhlmann MK, Sarkar S, Kaitwatcharachai C, Khilnani R, Leonard EF, Greenwood R, Levin NW: Adjustment of dry weight in hemodialysis patients using intradialytic continuous multifrequency bioimpedance of the calf. Int J Artif Organs 2004;27:104-109.

-8 Zhu F, Leonard EF, Levin NW: Extracellular fluid redistribution during hemodialysis: bioimpedance measurement and model. Physiol Meas 2008;29:S491-501.

-9 Seibert E, Zhu F, Kuhlmann MK, Henson R, Oribello AM, Girndt, M, Kotanko P, Levin NW: Slope-Analysis of Blood Volume and Calf-Bioimpedance Monitoring in Hemodialysis Patients. Nephrol Dial Transplant 2012;27:4430-4436.

-10 Zhu F, Kotanko P, Handelman GJ, Raimann J, Liu L, Carter M, Kuhlmann MK, Seibert E, Leonard EF, Levin NW: Estimation of normal hydration in dialysis patients using whole body and calf bioimpedance analysis. Physiol Meas 2011;32:887-902.

11 Liu L, Zhu F, G Raimann J, Thijssen S, Sipahioglu MH, Wystrychowski G, Kitzler T, Tetta C, Wabel P, Kotanko P, Levin NW: Determination of fluid status in haemodialysis patients with whole body and calf bioimpedance techniques. Nephrology (Carlton) 2012;17:131-40.

12 Official version of the German Anatomical Therapeutic Chemical (ATC) Classification with defined daily doses (DDD) 2009: Deutsches Institut für Medizinische Dokumentation und Information, Cologne, 2009.

-13 Lorenz CH, Walker ES, Morgan VL, Klein SS, Graham TP Jr.: Normal human right and left ventricular mass, systolic function, and gender differences by cine magnetic resonance imaging. J Cardiovasc Magn Reson 1999;1:7-21.

-14 Pluim BM, Lamb HJ, Kayser HW, Leujes F, Beyerbacht HP, Zwinderman AH, van der Laarse A, Vliegen HW, de Roos A, van der Wall EE: Functional and metabolic evaluation of the athlete's heart by magnetic resonance imaging and dobutamine stress magnetic resonance spectroscopy. Circulation 1998;97:666-672.

15 Geil S, Rao L, Menzel T, Genth-Zotz S, Wittlinger T, Voigtländer T, Mohr-Kahaly S: Determination of left ventricular mass by transthoracic three-dimensional echocardiography in patients with dilated cardiomyopathy. Z Kardiol 1999;88:922-931.

-16 Cutrone JA, Georgiou D, Khan S, Fischer H, Belardinelli R, Laks MM, Brundage B: Comparison of electron beam computed tomography scanning and magnetic resonance imaging quantification of right ventricular mass: validation with autopsy weights. Acad Radiol 1996;3:395-400. 


\section{Kidney \\ Blood Pressure Research}

Seibert et al.: cBIS Reduces Hypertension and LVH in HD Patients

17 Parfrey PS, Foley RN, Harnett JD, Kent GM, Murray DC, Barre PE: Outcome and risk factors for left ventricular disorders in chronic uraemia. Nephrol Dial Transplant 1996;11:1277-1285.

18 Parfrey PS, Foley RN, Harnett JD, Kent GM, Murray D, Barre PE: Outcome and risk factors of ischemic heart disease in chronic uremia. Kidney Int 1996;49:1428-1434.

-19 Levy D, Garrison RJ, Savage DD, Kannel WB, Castelli WP: Prognostic implications of echocardiographically determined left ventricular mass in the Framingham Heart Study. N Engl J Med 1990;322:1561-1566.

20 Patel RK, Oliver S, Mark PB, Powell JR, McQuarrie EP, Traynor JP, Dargie HJ, Jardine AG: Determinants of left ventricular mass and hypertrophy in hemodialysis patients assessed by cardiac magnetic resonance imaging. Clin J Am Soc Nephrol 2009;4:1477-1483.

21 Chan CT, Greene T, Chertow GM, Kliger AS, Stokes JB, Beck GJ, Daugirdas JT, Kotanko P, Larive B, Levin NW, Mehta RL, Rocco M, Sanz J, Schiller BM, Yang PC, Rajagopalan S, Frequent Hemodialysis Network (FHN) Trial Group: Determinants of left ventricular mass in patients on hemodialysis: Frequent Hemodialysis Network (FHN) Trials. Circ Cardiovasc Imaging 2012;5:251-261.

-22 Agarwal R, Alborzi P, Satyan S, Light RP: Dry-weight reduction in hypertensive hemodialysis patients (DRIP): a randomized, controlled trial. Hypertension 2009;53:500-507.

$\checkmark 23$ Cice G, Di Benedetto A, D'Andrea A, D'Isa S, De Gregorio P, Marcelli D, Gatti E, Calabrò R: Heart rate as independent prognostic factor for mortality in normotensive hemodialysed patients. J Nephrol 2008;21:704-712.

-24 Vonend 0, Rump LC, Ritz E: Sympathetic overactivity-the Cinderella of cardiovascular risk factors in dialysis patients. Semin Dial 2008;21:326-330.

25 Siddiqi L, Prakken NH, Velthuis BK, Cramer MJ, Oey PL, Boer P, Bots ML, Blankestijn PJ: Sympathetic activity in chronic kidney disease patients is related to left ventricular mass despite antihypertensive treatment. Nephrol Dial Transplant 2010;25:3272-3277. 